\title{
Research on Strategy of Nantong Traditional Craft Revitalization*
}

\author{
Yiyue Xiong \\ Jiangsu College of Engineering and Technology \\ Nantong, China 226007 \\ Jiangnan University \\ Wuxi, China 214122
}

\begin{abstract}
Nantong traditional craft has rich variety and various forms. It still continues to develop although having experienced repeated ups and downs. Over the past century, Nantong traditional crafts are sold well overseas and enjoy high reputation in the world. Since the middle 1990s, Nantong traditional craft industry develops slowly due to national policy adjustment, surpassed by that of Wuxi, Yangzhou, etc. Nantong municipal party committee leaders, craft masters, experts and scholars have made suggestions and expressed their views about how to revive Nantong traditional craft and to promote the industrial development of Nantong arts and crafts industry. This paper offers key analysis from several elements of the industry, namely product, platform, marketing, capital and talent, based on the characteristics of Nantong arts and crafts resources, and proposes the strategy for revitalizing Nantong traditional craft.
\end{abstract}

Keywords—traditional craft; revitalization; strategy

\section{INTRODUCTION}

The traditional craft refers to the craftsmanship and related products that have historical inheritance and national or regional characteristics, closely linked with daily life and mainly uses manual labor. It is a creative manual labor and individualized production of materials, having the characteristics that cannot be replaced by industrial production. Chinese traditional craft is widespread throughout the country, covering people's clothing, food, housing and transportation. Among the four batches of 1372 national intangible cultural heritage projects published by the State Council, a total of more than 300 projects are involved in the national costume projects of traditional art class, traditional skill class and folk class.

Foreign countries started earlier to research traditional craft with quite more mature and systematic achievements. The neighboring Japan and South Korea's some practices of

*Fund Project: [1]This paper is one of the staged achievements of Fund Program of Humanities \& Social Sciences Research from Ministry of

Education in 2017 of "Research on cross border integration of craftsman skills and modern design in the intangible cultural heritage of

Nantong"(Project No.: 17YJA760078).[2]This paper is one of the staged achievements of Fund Program of philosophy and Social Science of Jiangsu universities in 2017 of "The intangible culture in "Craftsman skills"

Innovation: a case study of board harrier kites"(Project No.

2017SJB1264).[3]This paper is one of the staged achievements of Nantong

City Social Science Fund Project 2017 of "Study on the Inheritance and

Innovation of Nantong Folk Art in the Construction of Harmonious Society" protection and development are worthy of our reference and learning. The Korean government enacted the Korean Cultural Property Protection Law in 1962 to focus on the protection and development of traditional craft. The Japanese government developed the Traditional Crafts Industry Revitalization Act in May 1974, taking industrial revitalization, national life enriching, and the realization of sound development of national economy as the goal.

In Taiwan, traditional craft created a report boom period of nearly 40 years from the anti-war victory to the 1990s. "Challenge 2008" program was launched in 2002, cultural and creative industries were included in the top ten plans of Taiwan's development, and as a result, Taiwan became one of the most successful areas in terms of traditional craft industry development. The Traditional Arts and Crafts Protection Regulations introduced in China in 1997 mainly defines the scope of arts and crafts, stipulates the traditional arts and crafts varieties and technique confirmation system, and implements 21 protection measures, including the establishment of archives, collection of representative works and confirmation of security classification.

In March 2017, the State Council agreed and forwarded the China's Traditional Craft Revitalization Plan developed by the Ministry of Culture, Ministry of Industry and Information, and Ministry of Finance. The Plan will strengthen the construction and theory of discipline and profession and technical research relating to traditional craft, and improve the design, production level and overall quality of traditional crafts, broaden traditional crafts' promotion, display, sales channels and other ten as the implementation focus.

On the whole, the research on traditional arts and crafts resources in our country has been extended from the simple protection and research of theory to strategy research of specific practical and effective practices for industrial development. But the author thinks that there are still some shortcomings. The theoretical circles' development and research of the traditional arts and crafts resources is broad and empty, the traditional crafts practitioners are too micro-specific and cannot form a theoretical overall study. How to integrate the macroscopic theoretical research and micro-practice research of traditional craft is the focus of this paper. 


\section{PROTECTION AND INHERITANCE OF NANTONG TRADITIONAL CRAFT RESOURCES}

Nantong is located at the intersection of river and sea. Since the Later Zhou Dynasty, land gradually formed at this place. With flat terrain, fertile soil, sufficient development, economic development and social progress, all walks of life gathered here, which promote the integration of north and south civilization, forming the scene of talents gathering, especially in the Ming and Qing Dynasties. Influenced by diversified culture, including that of $\mathrm{Chu}, \mathrm{Wu}$ and Yue, an inclusive regional culture was produced, forming the Nantong traditional craft resources with a wide range of varieties, rich content and diversified forms, providing a broad consumer market and rich cultural resources for cultural industrial development. Nantong traditional craft has a wide range of non-heritage projects, including five traditional craft projects of national intangible cultural heritage, namely Nantong blue printed cloth dyeing and printing technology, Nantong board Banyao kite production skills, Nantong dyed fabric technology, Nantong simulation embroidery techniques and Rugao bonsai modeling techniques, as well as other traditional craft projects, such as Nantong rosewood carving, Rugao silk blanket skills, Nantong colored silk embroidery, Nantong tie-dye technique, Hai'an crochet skills, Nantong woodblock New Year paintings, casting technology of Nantong copper incense burner, Nantong lantern skills, Nantong furniture production skills, Nantong Kesi skills, sea and sand kitchen painting; Nantong paper cutting, dough modeling, porcelain painting, Rugao sachet, Xingren picture mounting, bamboo carving, palm fiber weaving, reed weaving, cane weaving, silk clip, gourd craft, and other traditional craft projects of municipal intangible cultural heritage.

Currently, there are more than 140 enterprise members in Nantong Arts \& Crafts Industry, with an annual output value of 12 billion, of which $70 \%$ are exported, and the products include a total of nine categories and 30 varieties, such as mahogany, furniture, embroidery, clothing, toys, kites, metal casting, lacquerware and cloth.

Nantong is one of the enrichment areas of arts and crafts in Jiangsu Province. In 1970s-1990s, the embroidered clothing exported from Nantong exports to Europe and the United States accounted about $13 \%$ of the whole country, the exported craft caps accounted about $4 \%$, and the arts and crafts output value ranked second in Jiangsu (Suzhou first). Nantong Shen embroidery boutique and Rugao art tapestry were selected as the national gift; Nantong Kesi process cooperated with the domestic fashion luxury brand $\mathrm{Ne}$ - Tiger, and promoted the high fashion; The bamboo carving artists of Nantong launched a full set of bamboo furniture exclusively in the country; Nantong mahogany carving output accounted for half of that of the province, and was awarded the "Traditional Arts and Crafts Industry Base in Jiangsu Province."

How to achieve the revitalization of folk craft? Through the interview 1 with a number of arts and crafts masters in local Nantong, the author knows that these several masters all show their worry about arts and crafts industry development in Nantong. They also put forward a number of solutions and express their expectation about Nantong arts and crafts industry in the future.

$\mathrm{Wu}$ Yuanxin, vice chairman of China Folk Artists Association, chairman of the Municipal Artists Association, director of Nantong Blue Printed Cloth Museum holds the opinion that, first of all, we shall establish the arts and crafts industry base, gather the scattered small folk workshops at the foot of Langshan Mountain, set up the arts and crafts master or arts and crafts heritage base to provide development space; second is "going out", Nantong is one of the three "Chinese folk art villages," and its folk technology ranks the front of the country, so Nantong should go out to show its strength to expand its influence. The municipal folk association intends to organize the folk craft products of Nantong to hold an exhibition in Beijing; Third is "introduce in" to seize the opportunity to undertake the National Folk Crafts Fair, introduce the national folk arts and crafts to Nantong to open the horizon of Nantong folk artists, and further expand the visibility and reputation of Nantong while obtaining economic benefits.

Xu Junhua, Director of Nantong Kite Museum, holds the opinion that, the first is the popularization of folk craft, reinforce the mass base, combine the old craftsmen with the masses closely; the second is innovation: innovate the products in the premise of retaining craft skills to occupy the market and expand consumer groups. The third is the inheritance: get involved in the community, school and enterprise to show folk crafts and expand the influence.

Miao Jinwei, Secretary-General of Nantong Municipal Folk Artists Association, believes that we shall absorb talents from production-type protection through vocational education and social training; innovate products, update themes, break the vision constraints of old artists; pay special attention to it from government level, make capital investment and accumulate experience; innovate collaboratively, and construct jointly by the government, industry, enterprise and school; go out to promote, exhibit and display; cultivate the market, conduct joint development by combining tourism and cultural industry.

\section{STRATEGY OF NANTONG TRADITIONAL CRAFT REVITALIZATION}

In 2008, the article of Investigation of Current Nantong Arts and Crafts Industry Development and Countermeasures by Mr. Hu Jichun from Nantong Economic and Trade Commission was published in Review of Economic Research. This article proposes nine countermeasures for promoting arts and crafts industry development starting from Nantong arts and crafts industry development and characteristics. Ten years later, China's society, economy, industry has shown a new look, and hereby proposes the strategies for promoting Nantong traditional craft revitalization in terms of product, research and development, platform, capital and talents.

\footnotetext{
${ }^{1}$ It is the contents arranged by the author of the interview record after interviewing the folk art experts, including Director Wu Yuanxin, Director Xu Junhua, and Secretary-general Miao Jinwei.
} 


\section{A. To Create the Traditional Craft Cultural and Creative Products Combining Practice and Beauty}

Traditional arts and crafts products either have too conservative theme contents, or focus on cultural relic collection which results in small production capacity, or are positioned too low and only function as a traditional product with artistry being ignored. Nantong "Twelfth Five-Year Plan" Industrial Transformation and Development Planning mentions that the focus of arts and crafts is to vigorously develop tie-dye, embroidery, industrial shoes and hats, blue printed cloth and mahogany carving and other traditional arts and crafts industries, adhering to the fine tradition, introducing in the fashion elements, to promote the organic combination of traditional craft and modern technology, enlarge the scale and develop the brand.

Product innovation is the core of industrial development. Take the cultural and creative products development of the Imperial Palace as an example: court bead headset, Shangfang Baojian gel pen, bookmark of emperor and queen of Ming dynasty, mobile phone seat of imperial bodyguard, sun umbrella of "Flowers Ling", potted plant furnishing articles of master kung fu, tape with "I (the emperor) know", folding fan with "I (the emperor) am such a man" and so on. These products are full of rich culture of the Forbidden City with prices from several yuan to hundreds, and these cultural and creative products all have cultural elements of the Imperial Palace.

Nantong Kite Museum has done some attempts with respect to product development. The newly launched two pieces of works of "Blue Printing Seven-Star Banyao", and "Blue Printing Hexagonal Banyao" integrate the color features of blueprint cloth into traditional whistle Banyao, adding folklore meaning of this kind of kite, having more value of collection and appreciation. The works of "Longevity" and "God of Longevity" are made for the elderly, and they adopt the traditional longevity graphics, and the technique of expression combines modern expressions. "Great Unit Yao" and "Yao of Ancient Myth of Seven-Star" also make bold innovation in terms of graphics and techniques. In addition, a large number of cultural stationery supplies are developed, integrating joy into use with strong market reaction.

Nantong Blue Printed Cloth Museum launched the Chinese Zodiac blue printed doll series of toys, children's shoes and hats, bags and so on. Among them, cheongsam, umbrellas, fan, handbag, wallet, cushions, pillow, kerchief and wall hanging are very popular with people. Along with the blue printed national gift and national costumes, the blue printed cloth artistic products often appear in the international political arena, rendering waves of Chinese blueprint in the international community.

Theme selection, skill improvement, integrating into fashion, and the creation of arts and crafts cultural and creative products combining practice and beauty is the only way of product innovation.

\section{B. Promote the Construction of Traditional Craft Industry Base and Industry Cluster District}

The important carrier for development of traditional craft is the heritage base and industrial park. To make the main body of traditional craft industrial development bigger and stronger, we shall strengthen the development construction of traditional craft industry cluster as we strengthen the construction of economic projects and development zone.

The cultural and creative industrial comprehensive service platform cultivated with emphasis by Hangzhou - Hangzhou Creative Design Center aims to build an internationally renowned, first-class cross-strait experimental park for cultural and creative industry exchange and cooperation, the demonstration base integrating practice culture and technology, promote the transformation of industry-university-research cooperation achievements in cultural and creative field as well as the industry cluster district for brand promotion. Hangzhou Creative Design Center cooperates with Beijing Palace Museum to build the "Palace Museum (Hangzhou) Cultural and Creative Center", introduces in the Wuqing Golden Museum, good articles and equipment and other more than 60 Taiwan Arts and Crafts brands, sets up the cross-strait cultural and creative display and promotion platform of 5,000 square meters.

The Intangible Heritage Workshop, located at west of Nantong Jianghai Folk Culture Exposition Park, is invested and constructed jointly by Nantong Langshan Mountain Scenic Area Administrative Committee and Nantong Intangible Heritage Protection Center with a total construction area of about 4300 square meters and 14 residential buildings with Nantong local characteristics. At present, 18 countries (regions), provincial and municipal intangible cultural heritage projects and outstanding folk art projects have settled in the Intangible Heritage Workshop, among them, there are 4 national intangible traditional craft projects, namely Nantong blue printing cloth printing and dyeing skills, Nantong Banyao kite production skills, Nantong yarn-dyed fabric technology, and Nantong simulation embroidery skill; 5 provincial intangible traditional craft projects, namely, Nantong mahogany carving, Nantong colored satin embroidery skills, Nantong tie-dyeing skills, Nantong copper incense burner casting technology, and Nantong oak hazel furniture production skills; 8 municipal intangible traditional craft projects, namely, Nantong wood engraving, Nantong paper-cut, Nantong colored-lantern, Haimen gourd technology, Nantong Kesi, Nantong bamboo art, Nantong porcelain painting, and Nantong pyrograph. Through these traditional handicrafts, folk arts and crafts projects, the dynamic display publicity and live protection inheritance can be conducted in a better way.

Nantong 1895 Cultural and Creative Industrial Park is positioned as culture industry development of "living fossil of industrial civilization, new world of fashion creative", covering seven theme functions, such as creative workshops, creative design, creative exhibition, creative experience and others. In addition, the Nantong 1895 Cultural and Creative Industry Park also actively explores the road of industrial innovation and development around the five major industries, namely, cultural creativity, digital media, information service, handmade art and 
leisure tourism, as well as introduces the domestic and international professional team and talents. Taiwan Tai Chi Audio and Video Company, mint workshop, glass studio and other studios are introduced in. The park also increases communication with the local Nantong folk craft masters, introduces in silkwood exhibition hall and courtyard production and construction base, red sandalwood furniture boutique exhibition hall projects. Moreover, the carry out the interaction between Chinese arts and crafts colleges and universities with industry associations, and cooperate with Tsinghua University Academy of Fine Arts to set up training bases and offer classes regularly. Actively create six platform construction including research, forming, incubation, investment, trading and service, promote the construction of collaborative innovation center, contemporary handicraft innovation center as well as mainland - Taiwan cultural and creative cooperation park.

In addition, Nantong creates a batch of arts and crafts cultural industry cluster district with reasonable layout, distinctive features, and strong driving force and radiation in the characteristic town with concentrated folk arts and crafts. In 2005, Nantong City was named as the hometown of Chinese blue printing cloth and Chinese blue printing cloth art heritage base by China Society for the Study of Folk Literature and Art; in 2007, Nantong City was named as "hometown of China Banyao kite" by China Society for the Study of Folk Literature and Art in 2007; The "Kite" of Tongzhou District and "modern folk painting" of Rudong County, Nantong City, Jiangsu Province, have been listed in the annual "Chinese Folk Culture and Art Town" list by Office of the Ministry of Culture for two consecutive sessions, namely 2011-2013,2014-2016. In these folk literature and art towns, the government makes unified planning, supports and builds the characteristic industry cluster integrating arts and crafts product protection and development, display, exhibition, local tourism and rural tourism.

\section{Promote the Construction of Sales Channels and Electricity Business Platform for Traditional Craft Industry}

The 21 st century is the information age, and the important feature of information society is network. The traditional threelevel sales model of wholesalers, agents and distributors shows more and more of its conditionality. With the rapid development of network economy and e-commerce, the marketing model of arts and crafts products is also need to be changed.

Xiwang Village, Dingshu Town, Yixing, Jiangsu Province, is known as "China's First Village of Redware," and $80 \%$ of the peasant households are engaged in the production of dark-red enameled pottery. Once Xiwang Village faced difficulty in expanding market because it just waits for the customers to come, however nowadays, the redware managers in Xiwang Village all understand to make money by virtue of network. At present, the village has accumulated more than 200 online stores, and the e-commerce sales in 2015 amounted to more than 5200 million. Henglong E-commerce Industrial Park, China's first park taking redware as the theme, gathers the scattered reware e-commerce enterprises, providing new competitive power for the upgrade and transformation of redware traditional craft industry. The first batch of enterprises to settle in the park exceeds 50 enterprises, including 20 largescale e-commerce enterprises, and the annual online turnover is expected to exceed 500 million yuan.

On August 5, 2015, the official Taobao shop of the Palace Museum landed on Juhuasuan shopping platform. A total of 16,000 cultural and innovative products were closed on Juhuasuan shopping platform only within the day of August 5. The arts and crafts cultural and creative industry of Palace Museum has a brilliant future by virtue of the Internet. As the end of August 2014, the Palace Museum designed and developed a total of 6746 kinds of cultural products, in 2013, Palace Museum launched APP "Yin Zhen Beauty Map", and till the Ceramics Hall of Palace Museum as of April 2014, Palace Museum has launched 6 APP. It is expected that culture and innovation industry this year will bring about 900 million yuan of income to the Palace Museum. (In contrast, the annual ticket income of Palace Museum in 2013 was 700 million yuan, and cultural and innovative product income was more than 600 million yuan.)

The Implementation Opinions of Nantong Municipal Government on Accelerating the" Internet +" Action Plan also highlights to promote the innovation and development of Nantong intangible cultural heritage and traditional arts and crafts product, as well as the development of advertising creativity, animation games, digital content, digital publishing, copyright transactions and other emerging industries. Currently, there is no special arts and crafts industry e-commerce platform in Nantong. In addition to Shen Shou Art Museum and the Kite Museum, the vast majority of arts and crafts enterprises have no corporate website. One problem needs to be solved for the traditional craft enterprise workshop is that the publicity is made via the Internet and the mobile terminals with rare traditional craft enterprise workshop.

\section{Improve the Capital Credit Fund Guarantee System of Traditional Craft Industry}

The development of traditional craft requires strong capital support, in turn, the traditional craft industry will bring good returns to the capital, thus forming a positive circle. In June 2009, Nantong Economic and Trade Commission pointed out in a research report of traditional craft that, to strengthen the traditional folk art protection, first of all, we shall implement the existing supporting and incentive policy, make folk artists to restore the traditional craft production.

Moreover, it is necessary to integrate the existing policies and support funds that support the development of traditional craft industry, increase as appropriate the focus and share that support traditional arts and crafts industry, invest funds into talent training project of skill inheritance with emphasis, increase the special allowance for outstanding talents of arts and crafts, and the awards for unites and individuals who have made significant contribution to the development of traditional arts and crafts industry. Especially support the subsidies for service platform construction and industrialization projects as well as market expansion, external display and publicity and so on. 
Encourage financial institutions to innovate and produce the financial products and services suitable for traditional craft industry, provide "one-stop" services of centralized credit, credit rating, asset evaluation and loan guarantee, and guide the financial capital to make investment in arts and crafts industry to enhance the ability and strength of re-development.

At present, some local governments in China have set up the traditional craft industry protection and development fund and implemented the "apprenticeship" subsidy system. Hangzhou, Zhejiang Province, spent 2 million yuan annually to support the protection and development of key traditional arts and crafts since 1998. Moreover, key positions of important projects also enjoy the special allowance of $10-15 \%$ the wages. Yangzhou City of Jiangsu Province, allocates 1 million yuan annually for the protection and development of traditional arts and crafts; national master enjoy the allowance of 1,200 yuan per month for instructing apprentices, the provincial master of 1,000 yuan per month, and the national intangible cultural heritage inheritor of 8000 yuan each year.

As for blue printing cloth, tie-dye, reeling and mahogany carving that have formed on a scale in Nantong, the government can provide policy support, enterprises seek cooperation opportunities with other industries rely on their own strong resource advantages, attract social capital to expand, form cross-regional unified unit and create the products with industrial advantages.

The government should provide financial support, or make financial companies to support, the small scale companies, such as yarn-dyed fabrics, wood engravings, paper cut, engraved paper cut, silk cut and paste, dough modeling, colored-lantern, palm fiber weaving and reed weaving, as they have small product output with weak survivability.

The arts and crafts enterprises can enjoy a smooth and stable development only with sound fund guarantee system that integrates government funds, financial credit, social capital and nongovernmental floating money.

\section{E. Construction of All-round Comprehensive Traditional Craft Education and Personnel Training}

The key to the sustainable development of traditional craft lies in the cultivation of technical talents. The main inheritance ways of traditional craft mainly include academy inheritance, master to apprentice inheritance and family inheritance. With the accelerating change of traditional craft and market, the single inheritance mode also needs to be changed.

First, expand the mode of academy inheritance. We shall guide and encourage the establishment of arts and crafts related professional disciplines or the adoption of school-running mode of cooperation between master and colleges in key traditional craft areas, to innovate the teaching methods, accelerate the cultivation of professional and technical personnel, enrich the technician team and improve the staff's quality, against the local key traditional arts and crafts varieties. The representatives of academy inheritance include Ren Hang, master of engraved paper cutting and Ge Xueqiang, master of redware, graduated from Nantong Textile Vocational Technology College.
Second, improve the master to apprentice inheritance mechanism. Master to apprentice inheritance is the basic inheritance mechanism of the arts and crafts for thousands of years. The oral or mental instruction tradition of arts and crafts is determined based on industrial production mode. Success is benefited from individual's understanding and good fortune; after all, it takes time to grasp the manual skills. We shall establish new type of master to apprentice inheritance mechanism, develop and implement the subsidy plan and corresponding management methods for master teaching apprentice, to improve the enthusiasm of the master to teach. The representatives of master to apprentice inheritance include of a number of embroidery masters, and Zhang Liang, mahogany carving Master Zhu Yu's son in law.

Third is to make innovation to family inheritance. According to the survey, 54\% of Chinese folk arts are inherited within the family. Family inheritance refers to teaching or learning traditional manual skills within people having the direct relationship, generally adhering to the family rules of "father to son", "pass internally", "pass the people with their surname name". Affected by the family environment since childhood, father-to-son model is very conducive to the inheritance of arts. As a result, a new generation of successors for family inheritance has emerged: Wu Lingshu, blue printing cloth art master Wu Yuanxin's daughter, Jiao Huirong, tie-dye master Jiao Baolin's daughter, Li Le, silk carpets master Li Yukun's nephew, and Zhang Jinzhe, copper furnace master Zhang Zhiwei's son. But with the implementation of the family planning policy, the family inheritance is impacted greatly. Sharp reduction of population will inevitably lead to the lack of sufficient talent to inherit.

In addition, art and craft education shall be implemented from early childhood. Taking the key subject of "Research on the Development and Application of Local Cultural Resources in Art Course" of Jiangsu Province as the guide, Nantong City fully excavates Nantong local traditional arts and crafts cultural resources, prints the Nantong Local Art Experimental Textbook for primary school, junior high school and high school, and builds the local art and local culture course that is in line with the psychological characteristics and aesthetic needs of primary and secondary school students, and use all of them in classroom teaching. Rudong County prepares the teaching materials such as Feature Wearing and Rudong Folk Painting. Banyao kite, paper cut and other traditional folk craft courses are set in Gangzha District, Nantong City. Tongzhou District Experimental Primary School publishes six Ruichun intangible artistic books, namely Nantong Banyao Kite, Nantong Simulation Embroidery, Tongzhou Blue Printed Cloth, Rugao Puppet, Nantong Woodcut New Year Paintings and Nantong Paper Cutting.

Various colleges and universities in Nantong City pay more attention to "arts and crafts entering into the campus": In 2009, Nantong University set the Blue Printed Cloth Art Research Institute of Nantong University in Nantong Blue Printed Cloth Art Museum; in 2011, Nantong Agricultural Vocational and Technical College (now renamed Nantong Vocational College of Science and Technology) established a blue printed cloth skill heritance base; In 2012, Nantong Vocational College established Nantong mahogany carving base: Zhu Yu Carving 
Art Museum; in 2012, Nantong Textile Vocational and Technical College (now renamed Jiangsu Engineering Vocational and Technical College) established the cultural museums including Shen Shou Embroidery Workshop and Yarn-dyed Cloth art museum. In 2015, Nantong University established Nantong Intangible Cultural Heritage Research Institute.

In addition, arts and crafts masters are encouraged to teach at school, to promote the mutual docking between master studio and professional and technical institutions, build "college teachers + inheritors" teaching team, so as to cultivate the excellent artistic inheritors serving the teaching, research, and training. Chinese arts and crafts master Huang Peizhong, arts and crafts master Zhang Lei of Jiangsu Province are introduced in Nantong Textile Vocational and Technical College as excellent talents to engage in the teaching and research of traditional craft.

\section{CONCLUSION}

Nantong has a wealth of traditional craft resources, serving as an important part for the development of Nantong cultural industry. According to the characteristics of this city, Nantong develops a number of characteristic museum group, identifies a number of arts and crafts products that developed with priority. Some results have been achieved through the development in recent years. Entering into the new century, Nantong cultural industry development is facing unprecedented opportunities, and Nantong arts and crafts are full of vitality. In this situation, to re-examine the use of Nantong arts and crafts resources and realize the transformation from large arts and crafts city to strong arts and crafts city, seems to be more important and more urgent. Therefore, it is necessary to face the main problems existing in industry development and utilization of Nantong arts and crafts resources, use the strategies of Nantong arts and crafts resource development in terms of product, research and development, platform, capital and talents, make full use of the favorable conditions of all aspects, give play to their strengths, achieve the effective development and utilization of Nantong arts and crafts resources, so as to make the necessary contribution to the development of Nantong economy.

\section{REFERENCES}

[1] Cao Jinyang. Jianghai Liuyun: Exploitation and Utilization of Intangible Cultural Heritage in Nantong City [M] Jiangsu University Press.2011.11

[2] Zhang Fuye. Reflection on Protection and Development of Traditional Arts and Crafts [J] Creative Design Source. 2009.2

[3] Hu Jichun. Analysis of Nantong Arts and Crafts Industry [J]Jianghai Zongheng.2008.1

[4] $\mathrm{Hu}$ Jichun. Investigation on the Development of Nantong Arts and Crafts Industry and Countermeasures [J] Review of Economic Research. 2008.37

[5] Master Engraver Forced His Son-in-Law to be Apprentice, How to Revitalize the Folk Arts? [OL]Jiangsu Daily.2009.11.1

[6] Sun Yu. 16,000 Orders for the Palace Museum Gifts, Customers Say the Practicability needs to be Improved [OL] China News.2015.08.10

[7] Shen Xuemei, Liu Shinan. Nantong: Nourish the Sole using Art Education, Lead the Children to Beauty [OL] China Civilization Network. 2015.5.19
[8] Nantong Federation of Literary and Art. Nantong Federation of Literary and Art holds the Forum of "How to Develop and Inherit Nantong Arts and Crafts" [OL] Jiangsu Literature and Art Network.2012.11

[9] Zisha.Com. Yixing Makes Efforts to Promote the E-commerce Development Path of Redware Industry [OL] Zisha.Com.2015.05.18. 